\title{
The Making of a Test Mechanism for Occlusal Registration
}

\author{
Tanya Bozhkova ${ }^{1}$, Yavor Kalachev ${ }^{2}$, Stoyan Yankov $^{3}$ \\ ${ }^{1,2,3}$ Department of Prosthodontics, Faculty of Dental Medicine, Medical University, Plovdiv 4000, Bulgaria
}

\begin{abstract}
Among the different occlusal indicators the articulating paper is the most popular one. However the data in the available literature regarding the relationship between the thickness of the articulation paper and the area of the markings is rather contradictory. This laboratory study focuses on the possibilities for occlusal contacts registration obtained by different paper thickness. Our objective was to create an occlusal registration apparatus corresponding to the clinical conditions of maximum intercuspation. With the help of the apparatus for occlusal registration, we managed to make records of markings obtained from different paper thickness. The results obtained from our apparatus show a strong correlation between the occlusal indicator and the appearance of the occlusal markings
\end{abstract}

Keywords: Articulating paper, occlusal contacts, registration

\section{Introduction}

In clinical dentistry there are a wide range of methods used for registering the occlusal contacts [1]. The most popular method being the use of articulating paper [2, 3]. However there has been a dispute about the reliability of this method [4]. It has been widely accepted that the articulating paper mark size is an indication of the occlusal load [5]. According to some dental literature data the force of the occlusal contacts determines the intensity of the marks [6].

The data in the available literature regarding the relationship between the thickness of the articulation paper and the area of the markings is rather contradictory [7]. Some authors believe that large and dark marks show heavy load, whereas the light and small marks show lesser load [8]-[11]. Other researchers question this statement and claim the opposite [12]-[15]. According to Rosenberg, the intensity of the markings provides unreliable evaluation criteria for the occlusal load [16]. The variable size of the articulating paper markings area causes difficulty in the visual assessment of the occlusal load. Helms investigates if the occlusal indicators can affect the registration of the contacts [17].

Saad compares the number and the size of the occlusal contacts, obtained by different paper thickness subjected under different load. With thicker paper he registers bigger in size and number occlusal contacts in compare to the thinner paper. He also notices no significant rise in the number and the size of the occlusal contacts during different loading [14]. Carossa proves that the thicker articulation paper leaves bigger markings than the thinner paper [18]. Millstein determines that $200-\mu$ thick paper leaves fewer markings in compare to $40-\mu$ paper [19].

All these statements directed our attention to conduct a laboratory study of the possibilities for occlusal contacts registration obtained by different paper thickness.

\section{Aim}

To create an occlusal registration apparatus corresponding to the clinical conditions of maximum intercuspation.

\section{Materials and Methods}

In completion to the objective we designed an apparatus for registration of the occlusal contacts (named "AROC") in the conditions of maximum intercuspation.

Figure 1 shows an overall view of the apparatus for occlusal registration, whereas Figure 2 shows a schematic view of "AROC".

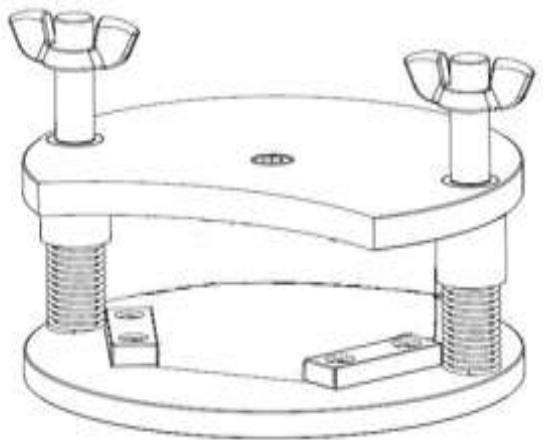

Figure 1: Overall view of "AROC"

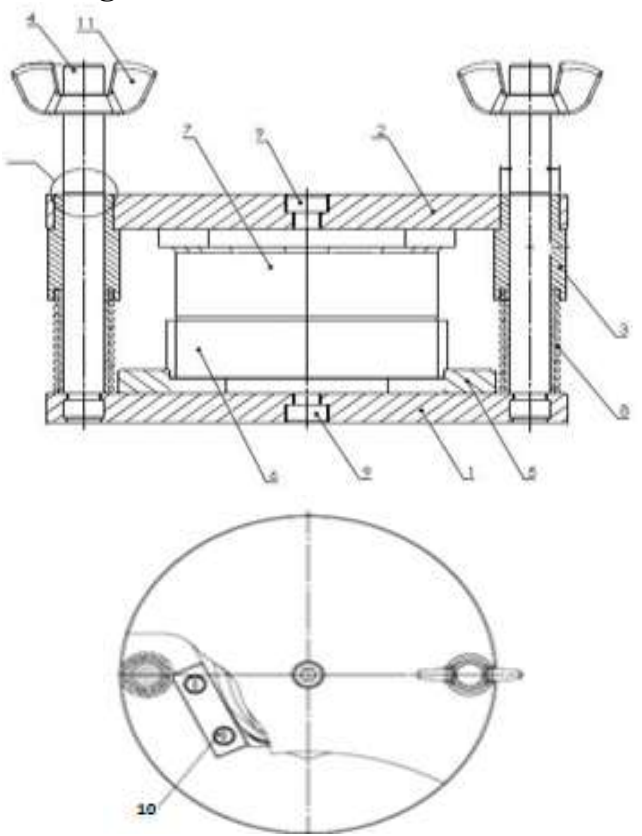

Figure 2: Schematic view of the main components 


\section{International Journal of Science and Research (IJSR) \\ ISSN (Online): 2319-7064 \\ Index Copernicus Value (2016): 79.57 | Impact Factor (2015): 6.391}

Chrome-nickel (Cr-Ni) steel was used in the fabrication of the prototype. Its main parts are shown in Figure 2:

1. Lower disc - 1 piece

2. Upper disc - 1 piece

3. Sleeve - 2 pieces

4. Threaded rod -2 pieces

5. Fixing plate -2 pieces

6. Lower jaw model

7. Upper jaw model

8. Spring - 2 pieces

9. Screw M 6x16 - 2 pieces

10. Screw M 4x16 - 4 pieces

11. Wing nut -2 pieces

The lower disk of the "AROC" makes up the base of the apparatus which has a specific thickness to withstand any possible deformation during load. The lower model is securely fixed to the upper side of the disk with a screw. To achieve correct alignment of the upper and lower models in the apparatus, the upper side of the disk has a dimensional straight line which coincides with the sagittal line of the lower cast. The lower cast has 2 fixing plates on either side to stabilise the casts and prevent shifting drug intercuspation. The upper jaw model is anchored to the lower surface of the upper disk with a screw. To ensure great visibility of the model the frontal part of the upper disk is cut off.

The height of the rod corresponds to the unloaded position of the casts in maximum intercuspation. There are two springs which are mounted on the rods to secure the opening of the models. The springs have linear characteristic, as the main load is directed through the axis. The wing nuts screwed on the rods limit the vertical movement of the upper disk.

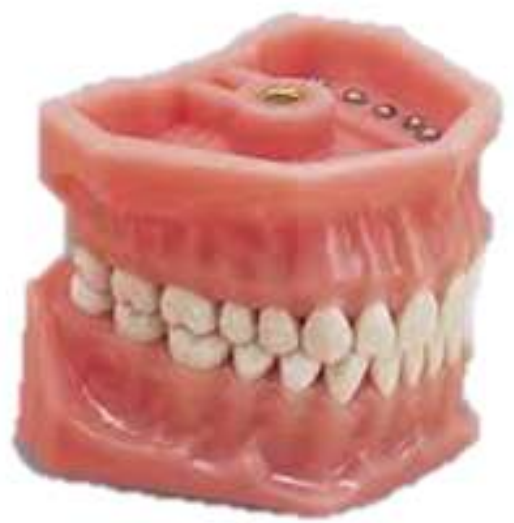

Figure 3: Standard phantom models Frasaco A-3Z

The standard phantom models have threads by default, through which they are fixed on the upper and lower disk. The screws were tightened with a torque wrench.

The apparatus we made have the following characteristics:

- It can precisely simulate vertical movements.

- It is made of chrome-nickel alloy that can withstand high loading and sustain no deformation during the tests.

- The casts can be tightly anchored and aligned in the same position, so that they stay still during intercuspation.

- The models are re-attachable.

For the occlusal registration we used $100-\mu$ and $40-\mu$ thick articulation paper (Bausch Arti-Check; Dr. Jean Bausch $\mathrm{GmbH} \& \mathrm{Co})$.
The apparatus "AROC" was placed in a hydraulic press (Silfradent, model 660) along with the mounted models. Maximum intercuspation was reached through tightening the main screw of the press. The applied load was $120 \mathrm{~kg}$ and was set by the hydraulic press manometer (Fig. 4). The inserted articulation paper between the arches was held by clamps, which secured the correct position of the paper.

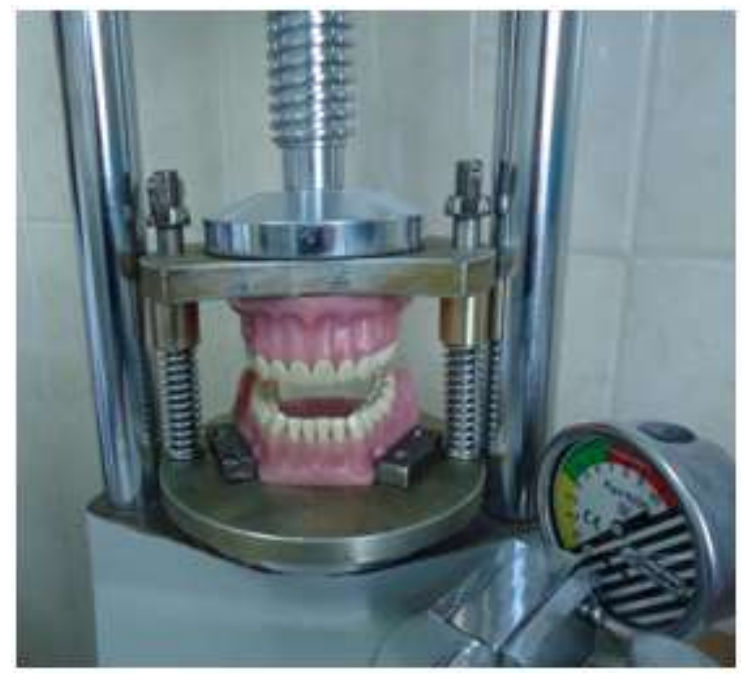

Figure 4: The apparatus "AROC"

We made 10 registrations of the occlusal markings from each paper thickness. The location, number and size of the markings on the occlusal surfaces of the teeth were recorded with a digital camera (Sony, model ILCE-6000). Each photo was made under the same conditions: $7 \mathrm{~cm}$ distance, autofocus, and no flash. The photos were processed and analysed through "ImageJ" software. The obtained results were tabulated and statistically analysed.

\section{Results and Discussion}

Statistical data from the $100-\mu$ and $60-\mu$ thick paper differ in size and number (Fig.5).

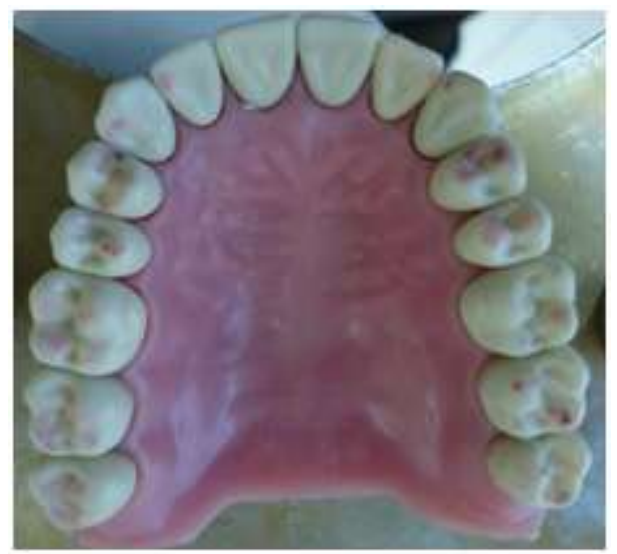

(a)

Volume 7 Issue 3, March 2018

www.ijsr.net

Licensed Under Creative Commons Attribution CC BY 


\section{International Journal of Science and Research (IJSR) \\ ISSN (Online): 2319-7064 \\ Index Copernicus Value (2016): 79.57 | Impact Factor (2015): 6.391}

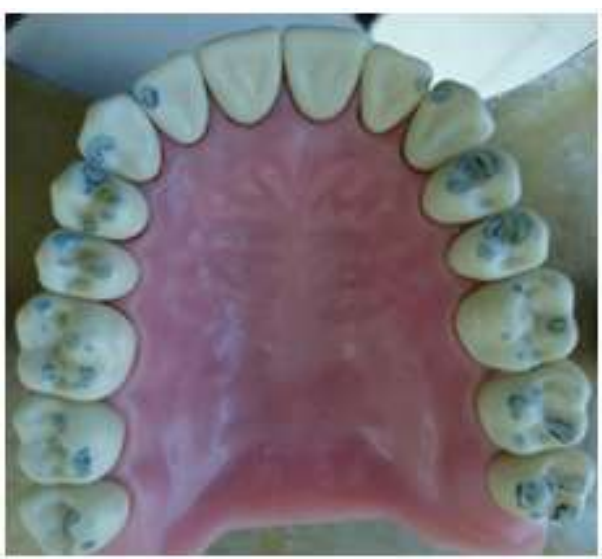

(b)

Figure 5: Occlusal marks from $100-\mu$ (a) and $60-\mu$ thick (b) articulation papers

We determined that the thicker occlusal paper left fewer in number and larger in size markings, whereas the thinner paper left smaller in size, but bigger in number markings.

The formula force/size $=$ load shows that the force is a constant value and when the marking area size increases, the load decreases. Resultant marks from thicker paper are larger in size, but contain less individual load and vice versa. The marks obtained from the thinner paper have smaller size and bigger individual load [3]. Therefore, we can conclude that the small area markings contain heavier load and the large area markings have lesser load.

By the means of our apparatus and this laboratory study we confirm the statement that the thicker articulating paper leaves bigger in size and fewer in number marks $[18,19]$.

However, the occlusal contact assessment based on articulating paper is unreliable and subjective, since it can be registered false positive contacts or fail to be registered other contacts $[4,5,14]$

\section{Conclusion}

The results obtained from "AROC" show a strong correlation between the occlusal indicator and the appearance of the occlusal markings. The occlusal registration apparatus that we designed can be utilised for testing different occlusal indicators.

\section{References}

[1] A. Sharma, GR. Rahul, ST. Poduval, K. Shetty, B. Gupta, V. Rajora, "History of Materials used for Recording Static and Dynamic Occlusal Contact Marks: a Literature Review," Journal of Clinical and Experimental Dentistry, 5(1), pp 48, 2013

[2] RB. Kerstein, "Missing the Mark: Accurate Observation of Occlusal Forces. Advances in CAD/CAM Dentistry," 1 (1), pp 11-13. 2008.

[3] RB. Kerstein, "Are Articulating Paper Labelings Reliable Indicators of Occlusal Contact Force?," Dental Products Reports Technique Guide, 8, pp 43, 2000.
[4] P. Millstein, A. Maya, "An Evaluation of Occlusal Contact Marking Indicators," Journal of American Dental Association,132 (9), pp. 1280-1286, 2001.

[5] J. Carey, M. Craig, RB. Kerstein, et al, "Determining a Relationship between Applied Occlusal Load and Articulation Paper Mark Area," The Open Dentistry Journal, 1, pp. 1-7, 2007.

[6] KW. Boening, MH. Walter, "Computer-aid Edevaluation of Occlusal Load in Complete Dentures," Journal of Prosthetic Dentistry, 67 (3), pp. 339-44, 1992.

[7] S. Qadeer, R. Kerstein , RJY. Kim, Huh JB, SW. Shin, Relationship between Articulation Paper Mark Size and Percentage of Force Measured with Computerized Occlusal Analysis. The Journal of Advanced Prosthodontics, 4(1), pp. 7-12, 2012.

[8] KA. Harper, DJ. Setchell, "The Use of Shimstock to Assess Occlusal Contacts; A Laboratory Study. International Journal of Prosthodontics, 15 (4), pp. 347-352, 2002.

[9] I. Kleinberg, "Occlusion Practice and Assessment," Oxford, England, Knight Publishing, pp. 128, 1991.

[10] C. McNeil, "Science and Practice of Occlusion. Carol Stream, Quintessence Publishing, pp. 421, 1997.

[11] J. Okeson, "Management of Temporomandibular Disorders and Occlusion," 5th ed. St. Louis, MO, CV Mosbyand Co, pp. 416,418,605, 2003.

[12]P. Millstein, "An Evaluation of Occlusal Contact Marking Indicators: A Descriptive, Qualitative Method. Quintessence International,14, pp. 813-818, 1983.

[13] P. Millstein, "Know Your Indicator," Journal of the Massachusetts Dental Society, 56 (4), pp. 30-1, 2008.

[14] MN. Saad, G. Weiner, D. Ehrenberg, S. Weiner, "Effects of Load and Indicator Type upon Occlusal Contact Markings," Journal of Biomedical Materials Research Part B: Applied Biomaterials. 85 (1), pp. 18-22, 2008.

[15] V. Sidana, N. Pasricha, M. Makkar, S. Banwait, "Computerized Occlusal Analysis," Indian Journal of Dental Sciences, 5 (2), 2013.

[16] WL. Maness, "Laboratory Comparison of Three Occlusal Registration Methods for Identification of Induced Interceptive Contacts," Journal of Prosthetic Dentistry, 65 (4), pp. 483-7, 1991.

[17] RB. Helms, TR. Katona, GJ. Eckert, "Do Occlusal Contact Detection Products Alter the Occlusion?" Journal of Oral Rehabilitation, 39(5), pp. 357-363, 2012.

[18] S. Carossa, A. Lojacono, G. Schierano, P. Pera, "Evaluation of Occlusal Contacts in the Dental Laboratory: Influence of Strip Thickness and Operator Experience," The International Journal of Prosthodontics, 13 (3), pp. 201-204, 1999.

\section{Author Profile}

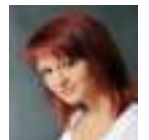

Tanya Bozhkova received her DDS degree in Medical University Plovdiv, Faculty of Dental Medicine, Plovdiv, Bulgaria in 2012 with the high grade point average. From 2013 she has been a Ph.D. student in the Department of Prosthodontics and in 2016 she has been employed as an assistant professor in the same department. Dr Bozhkova received her Ph.D. degree from Medical University Plovdiv in 2017. She is an active member of the: Bulgarian Dental Union (BDU), Bulgarian Scientific Dental Association and Balkan Scientific Society (BaSS).

Faculty of Dental Medicine, Medical University, Plovdiv, Bulgaria. 3 Hristo Botev blvd., Plovdiv, Bulgaria 